\title{
Workforce Training and Management Challenges in the Contemporary Smart Manufacturing (SM)
}

\author{
Artyom Kravchenko
}

\begin{abstract}
Smart manufacturing (SM) is gaining momentum as a new technological advancement of the manufacturing sector. It offers numerous advantages such as productivity, quality, and performance enhancements. A smooth transition of today's manufacturers to SM is impossible without adequately trained and skilled workforce, while the current lack of tech talent and the massive retirement of Baby Boomers cause additional workforce-related challenges in the industry. This article offers strategies for manufacturing businesses to hire and retain proper talent, to determine the right technological specialties they require, and to develop new effective means of workforce management in the context of a smart factory.
\end{abstract}

Keywords: smart manufacturing, cyber-physical systems, smart factory, automation, robotics, workforce management, data-based sensors

The $21^{\text {st }}$-century manufacturing is facing new challenges such as frequent product innovations, a shift from mass production to mass customization, as well as continuous technology integration. All these changes are enabled by the adoption of smart manufacturing (SM) - a new manufacturing model based on real-time data and technology use. SM is based on the intensified, pervasive application of networked information-based technologies throughout the manufacturing and supply chain enterprise [1]. It offers incredible innovation possibilities for the entire manufacturing system, the untapped potential of product quality improvement, productivity increases, energy efficiency improvement, and safer manufacturing spaces.

Despite the growing popularity of SM, the concept is still poorly understood. According to a comprehensive definition by the National Institute of Standards and Technology (NIST), SM represents "fully-integrated, collaborative manufacturing systems that respond in real time to meet changing demands and conditions in the factory, in the supply network, and in customer needs" [2]. The SLMC definition portrayed SM as an "ability to solve existing and future problems via an open infrastructure that allows solutions to be implemented at the speed of business while creating advantaged value" [2]. In other words, SM is a new stage of manufacturing evolution enabled by the technological connectivity, advanced access to data contextualization, and integration of data from multiple open and vendor applications.

SM incorporates the state-of-the-art technology such as cyber-physical production systems, internet of things, automation, big data analytics, and cloud computing into traditional 
manufacturing. These technologies are new for the manufacturing sector, and their effective implementation involves a resourceful, adequately trained workforce [3]. Counter to numerous fears about technology ousting people from their workplaces, smart factories offer an added employment potential. The evolution of manufacturing from a manual and static industry towards self-organizing, dynamic, and demand-driven involves key dimensions - equipment, workforce, materials and supply chain, business processes, platform, and facility and environment. The manufacturing workforce thus plays an essential role in progressing the sector from a simple break-fix system of human involvement to the introduction of specialized robots, creation of the augmented workforce, adaptive simple collaborative robots, and a further evolution toward the human-machine collaborative workforce [4]. With gradual adoption of SM in industrial facilities worldwide, technology-based manufacturing jobs are expected to experience a rise in demand, thus creating new positions in direct manufacturing and non-manufacturing sectors.

The value of SM integration in any country's manufacturing sector is enormous. ITenabled smart factories and supply networks are regarded as better responding to national interests and strategic imperatives. SM is also seen as able to revitalize the industrial sector by boosting global competitiveness and exports, provision of sustainable jobs, and radically improved performance combined with manufacturing innovation [1]. However, flawless operation of smart factories is possible only under the condition of broad-based involvement of skilled and appropriately trained workforce, which becomes a contemporary challenge for SM advancement.

\section{Smart Workforce for Smart Manufacturing}

While manufacturing progresses at an unprecedented pace today due to high-tech innovations and advanced industrial solutions, the weakest point of industrial progress is access to skilled labor force capable of operating smart factories and keeping pace with the rapidly evolving manufacturing technology [5]. Today's innovation is talent-driven and depends on the quality and availability of skilled labor such as researchers, analysts, and engineers. This

criterion determines the business's manufacturing competitiveness, so companies embracing SM now face the challenge of finding and hiring employees with the right skillset.

Unfortunately, the epoch of fast technological progress in the industrial sector has overlapped with another major trend of demographic nature. At present, large populations of 
baby boomers are retiring, while workforce requirements of the manufacturing sector grow. As a result, the gap between available and required skilled labor widens and leaves thousands of manufacturing jobs (e.g., machining, mechatronics, engineering, robotics, automation) unfilled. Thus, while most companies invest large budgets into modern equipment and operations for the sake of keeping their competitive position neglect a vital component of business success - hiring, training, and retaining smart workforce able to operate a smart factory.

SM is now seen as one of promising, scalable solutions to securing the necessary educated, trained workforce in manufacturing. The combination of quick technology adoption, massive retirements, and reducing interest of young people in manufacturing specialties poses serious challenges to the advancement of this sector, while SM brings about beneficial changes to the manufacturing labor force. As soon as a company starts implementing SM, its employees face the need to acquire additional training to maximize the new technology's potential and ROI [6]. These educational interventions may be further applied for developing the flexible dynamic workforce of the future. Together with better-trained current workforce, companies utilizing SM may attract new employees - the representatives of the next generation. Techsavvy Millennials are fully competent in web tools and innovative technology, able to utilize big data, and keeping pace with the rapidly evolving manufacturing technology. Such a combination of educating the present workforce and attracting the young talent pool is a winning strategy for any business serious about adopting SM in the long run.

The ways in which SM is going to impact the current manufacturing workforce include:

- Workforce augmentation with collaborative robots;

- Greater implementation of mobile technology to give workers on the factory floor access to real-time data analytics and vital alerts;

- Integration of advanced analytic and AI solutions for better decision-making;

- Transition from subtractive to additive manufacturing by means of 3D printing;

- Provision of access to critical information, interactive work instructions, and standard operating procedures with the help of wearables and immersive technology [7].

These methods are already applied at innovative SM enterprises such as those of Ford, HP, Volkswagen, and many other industrial giants. As a result of such innovations, factory 
employees become augmented by digital systems, work side by side with robots, and wear tracking bodysuits and additional wearables for efficient real-time interaction with production and data processing systems. Being able to function productively in such data-centric manufacturing settings requires a specific skillset from current and new employees, so strategies for developing smart workforce gain significance as a forward-looking investment into manufacturing agility.

\section{Strategies for Developing Smart Workforce}

While in the1950s, over one-third of the U.S. private-sector workforce was employed in manufacturing, while in 2012, the percentage barely reached $10 \%$ [8]. This trend follows a broader historical process of transitioning from low-skilled, manual labor to higher-valueadded production relying on highly-skilled, tech-savvy labor force. The manufacturing sector has evolved dramatically within the past half of a century due to acceleration of industrial cycles and pressure for technology adoption. Requisite manufacturing skills have been changing together with the sector and now include:

- Sense-making (an ability to deal with complex situations);

- Digital literacy;

- Novel, adaptive thinking;

- Social intelligence and strong communication skills;

- Computational thinking;

- Design mindset;

- Cross-cultural competency;

- Ability to collaborate virtually;

- Cognitive load management;

- Ability to work across multiple disciplines [8].

Possessing of these skills suggests the ability of modern manufacturing employees to navigate through a high-tech, information-loaded, quick, and multidimensional industrial framework. However, under the conditions of severe lack of tech-savvy manufacturing workforce, forward-looking manufacturers need to invest time and effort into educating and nurturing talent in-house. The greatest problems manufacturing entities now experience include finding experienced employees, upskilling the current workforce, and onboarding new employees [5]. 
These business pressures may be solved with workforce development strategies that help to close the skills gap effectively. Some of the most realistic solutions include developing a strong onboarding process and creating a formal in-house training program. Companies may also encourage continuous education and upskill trainers to help the company sustain a highly skilled workforce in the conditions of fast innovation. Another helpful solution is to establish smart training initiatives by partnering with local educational establishments and national training providers to give graduates on-the-job training and apprenticeships. Such collaborative schemes are likely to provide valuable competency-based learning to graduates, thus helping them to acquire real-world skills and get focused educational content for completing on-the-job requirements [5].

As one can see, manufacturing enterprises' transition to SM causes serious changes for the workforce. Some roles of employees may face realignment to support new processes and

capabilities (e.g., virtual and augmented reality, data visualization), while other roles may become obsolete, replaced by robotics, process automation, and AI. All these changes have to be properly planned and managed because a motivated, skilled workforce is instrumental for the SM integration success [6].

\section{SM Workforce Management}

As manufacturing progresses towards a more high-tech, interconnected workplace, so do the workforce management strategies. The process of making the SM workforce more resourceful is indispensably connected with training employees and providing them with timely and effective assistance in real time. These objectives may be accomplished by means of worker activity-related data capturing with a variety of sensors and actuators, also enabled with the SM functionality. Data derived from such sensors and processed with advanced analytical systems may provide valuable workforce information such as location, configuration, motion, actions, etc. [3].

The most promising technology to be used for workforce management at smart factories is radio frequency identification (RFID). RFID sensors are expected to provide accurate data on entity identification, location, and tracking. Another option considered for smart factories is the use of vision-based sensors; with their help, worker activities in the working environment can be accurately captured for further analysis. Wearable sensors also possess a huge potential in terms of sensing and monitoring workers in smart manufacturing; 
accelerometers enable measurements of acceleration and directions, gyroscopes can provide data on angular velocities, while electromyographers measure muscle tension changes [9]. However, the latter method is criticized for creating physical inconvenience and trouble for workers during the performance of work activities.

\section{Conclusion}

As the presented evidence suggests, SM is a viable innovative solution for invigorating the present-day manufacturing sector with new technology, new workforce, and new approaches. Due to the deeper integration of tech advancements into manufacturing operations, manufacturing recovers the interest of young generation in employment in this area and achieves greater performance, product quality, and competitiveness. Moreover, counter to the commonplace fears and criticisms about technological progress ousting people from jobs and leaving large populations unemployed, the transition to SM promises additional job positions. This proves to be true only for low-skilled, manual jobs, which are indeed giving way to robotics and automation. However, the demand for higher-order technical skills and knowledge such as engineering, robotics, big data analytics, and related specialties, is expected to rise exponentially soon.

Smart manufacturing is the matter of the present, not of the distant future. Thus, it is imperative for businesses to develop proactive steps to hire, train, and retain smart workforce able to operate their smart factories and move their business forward. By using the strategies mentioned in this article and investing in people alongside with technology, manufacturers may anticipate and avoid the talent gap at their facilities to embrace the SM concept in full and take advantage of the improved productivity, production capacity, product quality, and ROI that it offers.

\section{References}

1. Davis J, Edgar T, Porter J, Bernaden J, Sarli M. Smart manufacturing, manufacturing intelligence and demand-dynamic performance. Computers \& Chemical Engineering 2012; 47: 145-156.

2. McKewen E. Smart manufacturing requires a new kind of workforce (part 4 of 6).

CMTC. URL: https://www.cmtc.com/blog/smart-manufacturing-requires-a-new-kindof-workforce-now-part-4-of-6 [accessed 2019-04-09]

3. Al-Amin M, Qin R, Tao W, Leu MC. Sensor data based models for workforce management in smart manufacturing. Proceedings of the 2018 IISE Annual Conference. URL: https://par.nsf.gov/servlets/purl/10083239 [accessed 2019-04-09]. 
4. Accenture. High performance. Delivered. 2019. URL: https://www.accenture.com/_acnmedia/PDF-5/Accenture-804893-Smart-ProductionPOV-Final.pdf [accessed 2019-04-08]

5. Kunz J. Building a smart manufacturing workforce. Industrial Machinery Digest. 2018. URL: https://industrialmachinerydigest.com/industrialnews/features/workforce-development/building-a-smart-manufacturing-workforce/ [accessed 2019-04-08]

6. Burke R, Mussomeli A, Laaper S, Hartigan M, Sniderman B. The smart factory: responsive, adaptive, connected manufacturing. Deloitte Insights. URL: https://www2.deloitte.com/insights/us/en/focus/industry-4-0/smart-factory-connectedmanufacturing.html [accessed 2019-04-07]

7. Hobbs A. Complete guide: 10 smart factory trends to watch in 2019. Internet of Business. URL: https://internetofbusiness.com/complete-guide-10-smart-factorytrends-to-watch-in-2019/ [accessed 2019-04-05]

8. McCormack R. ReMaking America. Washington, DC: Alliance for American Manufacturing, 2013.

9. Kumar A. Methods and material for smart manufacturing: additive manufacturing, internet of things, flexible sensors and soft robotics. Manufacturing Letters $2017 \mathrm{Dec}$. DOI: $10.1016 /$ j.mfglet.2017.12.014 